\title{
Comparative study between serum level of hepatocyte growth factor and CA-125 in patients with suspicious malignant adnexal masses
}

\author{
Ziad Mansour Ahmed ${ }^{1 *}$, Helmy Helmy Abdel Satar ${ }^{1}$, Moyassar Ahmed Zaki ${ }^{2}$, \\ Hassan Mansour Hassan ${ }^{1}$
}

\footnotetext{
${ }^{1}$ Department of Obstetrics and Gynaecology, Faculty of Medicine, Alexandria University, Egypt

${ }^{2}$ Department of Chemical Pathology, Faculty of Medicine, Alexandria University, Egypt
}

Received: 08 December 2016

Accepted: 13 December 2016

\section{*Correspondence:}

Dr. Ziad Mansour Ahmed,

E-mail: ziad.mansour87@gmail.com

Copyright: (C) the author(s), publisher and licensee Medip Academy. This is an open-access article distributed under the terms of the Creative Commons Attribution Non-Commercial License, which permits unrestricted non-commercial use, distribution, and reproduction in any medium, provided the original work is properly cited.

\begin{abstract}
Background: Hepatocyte growth factor has been described to be increased in different cancers. The aim of the present study is to evaluate as a screening marker the serum level of Hepatocyte growth factor among suspicious adnexal masses as compared to serum levels of CA125.

Methods: The present study included 80 female patients who are admitted to the Gynecology unit in Elshatby Maternity University Hospital divided into two groups. Forty patients with benign gynecological conditions (control group) and 40 patients with suspicious malignant adnexal masses (cases group). Preoperative blood samples were withdrawn from all patients of both cases and control group to assess the level of serum hepatocyte growth factor (HGF) and serum cancer antigen 125 (CA 125). Both were quantified using ELISA technique.

Results: Out of the 40 cases with suspicious malignant adnexal masses, 35 had ovarian cancer while five only were borderline. Patients with ovarian carcinomas had significantly higher preoperative HGF and CA 125 serum levels than patients with borderline pathology. Patients with borderline tumors had a significantly higher serum HGF and CA 125 levels than patients with benign gynecological conditions in control group.

Conclusions: HGF in serum was elevated in $71 \%$ of patients with suspicious malignant adnexal masses proved to be ovarian cancer by histopathology using a quantitative ELISA. HGF can be used as a screening tool for ovarian cancer.
\end{abstract}

Keywords: Hepatocyte growth factor, Ovarian cancer, Suspicious malignant adenxal masses

\section{INTRODUCTION}

Ovarian cancer is the seventh most common cancer in women worldwide. ${ }^{1}$ The epidemiology of ovarian cancer is multifactorial with hormonal, genetic, environmental factors related directly or indirectly to carcinogenesis. Early stages of ovarian cancer (I/II) are difficult to diagnose because most symptoms are vague, it is infrequently diagnosed until it spreads and advances to later stages (III/IV). ${ }^{2}$ CA125 is not recognized as a sensitive test for early ovarian cancer, with a reported sensitivity of $50 \%$ in early-stage disease. ${ }^{3}$ There has been a considerable effort in the research, development and improvement of novel biomarkers applicable to the diagnosis and management of epithelial ovarian cancer. $^{4-6}$
Hepatocyte growth factor (HGF) is a multifunctional growth factor, mainly produced by mesenchymal-derived cells. $^{7-10}$ Within the ovary, HGF controls several key functions which collectively organize the growth and differentiation of ovarian follicles; these include cell growth, steroidogenesis, and apoptosis within theca cells and/or granulosa cells. ${ }^{11}$ Activation of the HGF/c-Met signaling pathway may lead to proliferation, enhanced cell motility, and angiogenesis. High levels of HGF and c-Met have been found in several human cancers. ${ }^{12-17} \mathrm{C}$ Met is expressed in normal ovarian surface epithelium. ${ }^{18}$ Its also over-expressed in ovarian cancer. ${ }^{19,20}$

The aim of the present study is to evaluate as a screening marker the serum level of Hepatocyte growth factor among suspicious adnexal masses as compared to serum 
levels of CA125.The ultimate goal of this study is to test that if serum hepatocyte growth factor can be used as a screening tool for ovarian cancer.

\section{METHODS}

This is a randomized prospective study. Eligible for the study were 80 female patients, 40 of which were diagnosed with a suspicious malignant adnexal mass appointed for laparotomy at Gynec Oncology unit at Elshatby Maternity Hospital, University of Alexandria, Egypt and 40 patients with benign gynecological conditions. We were able to collect preoperative blood samples from all 80 patients in the period from October 2015 till July 2016. Informed consent was obtained from all participants. Patients files were reviewed to obtain data regarding age at diagnosis, menstrual status, medical and surgical history, ultrasound and computed tomography findings, histology, and stage of the disease. All patients were surgically staged according to the International Federation of Gynecology and Obstetrics (FIGO) staging system. Furthermore, all histologic slides were reviewed by Pathology department in Faculty of Medicine, University of Alexandria.

\section{Serum analysis}

All serum samples were collected preoperatively. CA 125 was analyzed using chemiluminometric immunoassays on the Adiva Centaur XP immunoassay analyzer. The serum levels of HGF were quantified using a commercially available enzyme immunoassay according to the manufacturer's instructions (Quantikine R\&D Systems, Inc. Minneapolis, MN 55413, USA).The analyses were performed according to the manufacturer's instructions.

\section{Statistical analysis of the data}

Data were fed to the computer using IBM SPSS software package version 20.0 .

Qualitative data were described using number and percent. Comparison between different groups regarding categorical variables was tested using Chi-square test.

Quantitative data were described using mean and standard deviation for normally distributed data.

For normally distributed data, comparison between two independent population was done using independent t-test while more than two population were analysed Ftest (ANOVA) to be used. For abnormally distributed data, Mann Whitney test (U-test) was used.

\section{Receiver operating characteristic curve (ROC)}

It is generated by plotting sensitivity (TP) on $\mathrm{Y}$ axis versus 1-specificity (FP) on $\mathrm{X}$ axis at different cut off values. The area under the ROC curve denotes the diagnostic performance of the test. Area more than $50 \%$ gives acceptable performance and area about $100 \%$ is the best performance for the test. The ROC curve allows also a comparison of performance between two tests.

Significance test results are quoted as two-tailed probabilities. Significance of the obtained results was judged at the $5 \%$ level.

\section{RESULTS}

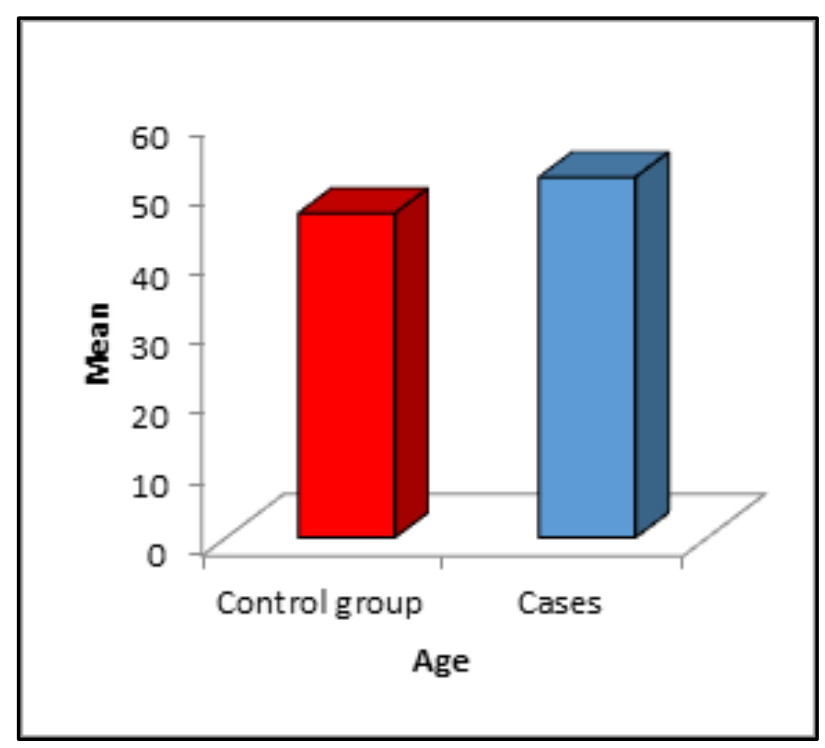

Figure 1: Comparison between two studied groups regarding age.

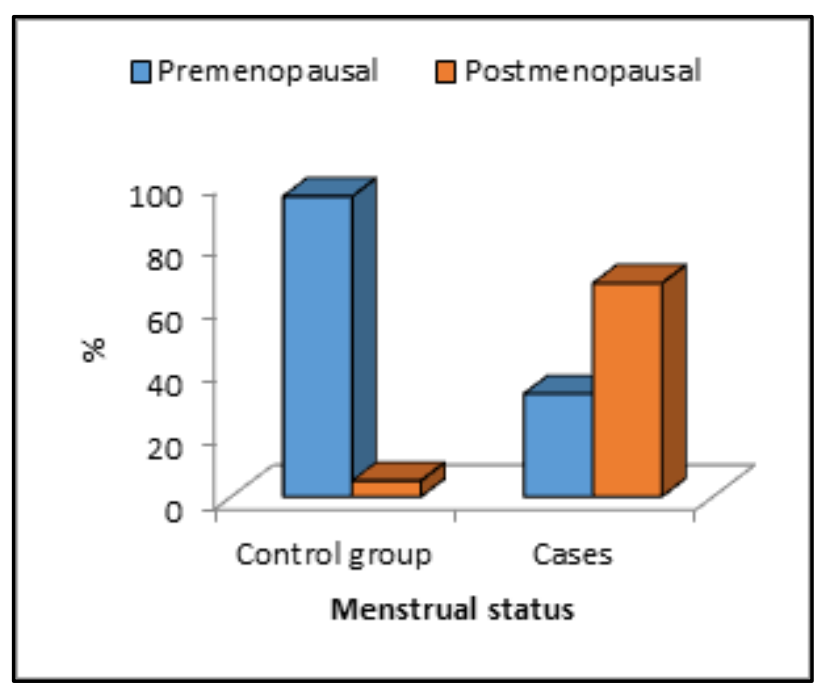

Figure 2: Comparison between two studied groups regarding menstrual status.

The patients were diagnosed with malignant epithelial tumors, borderline tumors and benign gynecological pathologies. The case groups were 40 patients including all suspicious malignant masses and control group were 40 cases with benign gynecological conditions. 


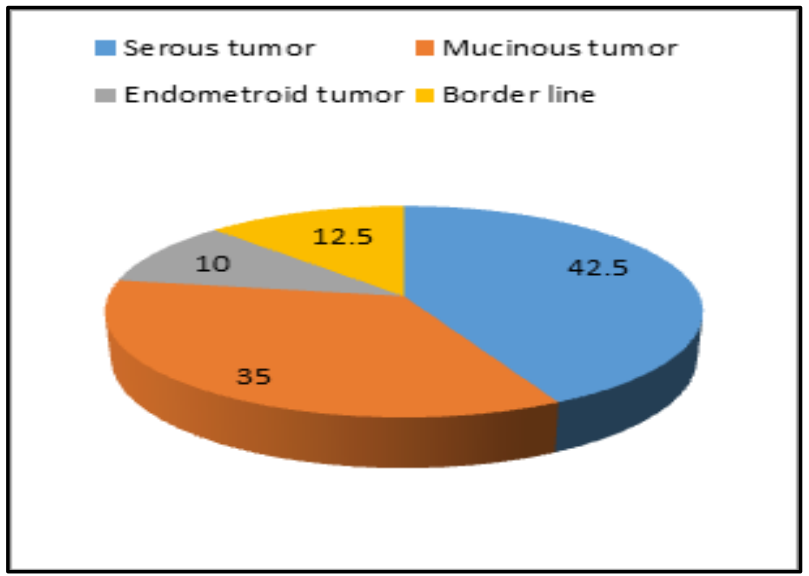

Figure 3: Pathological finding in the cases group.

In this study, the mean age in cases was $60.5 \pm 12.06$ while in control it was $46.33 \pm 6.94$. There was $38(95 \%)$ patients in premenopausal status in control group while patients in postmenopausal status were only $2(5.0 \%)$ and in cases, the group was $13(32.5 \%)$ and $27(67.5 \%)$ in premenopausal and postmenopausal status respectively. There was the significant statistical difference between the two studied groups regarding age and menstrual history $(\mathrm{P}<0.05)$.

Regarding imaging modalities used in this study, we found that there was a significant increase in detection of ascitis in patients using CT scan (55\%) compared to U/S $(32 \%)$.

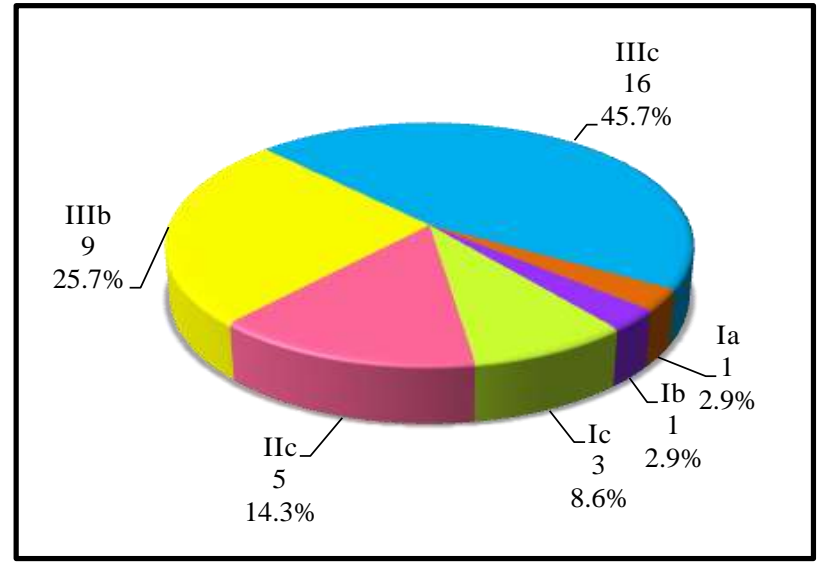

Figure 4: Distribution of studied cases (malignant) regarding stage.

\section{Histopathological findings in the cases group}

As regard histopathological finding, the most frequent was serous cystadenocarinoma $(42.5 \%)$ and mucinous cystadenocarinoma $(35 \%)$ followed by endometrioid adneocarinoma (10\%).

Regards the staging of the malignant cases in the present study, $5(14.3 \%)$ cases were stage I (Ia, Ib, Ic were $2.9 \%$, $2.9 \%$ and $8.6 \%$ respectively), 5(14.3\%) cases were Stage II, $25(71.6 \%)$ cases were Stage III (IIIa and IIIb were $25.7 \%$ and $45.7 \%$ respectively).

Table 1: Relation between different tumor markers and histopathological findings.

\begin{tabular}{|c|c|c|c|c|c|c|c|}
\hline $\begin{array}{l}\text { Tumor } \\
\text { marker }\end{array}$ & Histopathology & No. & Mean & S.D. & Min. & Max. & p \\
\hline \multirow{4}{*}{ HGF } & Serous cystadenocarcinoma & 17 & 2467.7 & 1368.1 & 1150.0 & 6246.6 & \multirow{4}{*}{$0.008 *$} \\
\hline & $\begin{array}{l}\text { Mucinous } \\
\text { cystadenocarcinoma }\end{array}$ & 14 & 1559.6 & 210.0 & 1300.0 & 1839.8 & \\
\hline & $\begin{array}{l}\text { Endometroid } \\
\text { adenocarcinoma }\end{array}$ & 4 & 1374.4 & 136.6 & 1213.5 & 1532.0 & \\
\hline & Border line tumor & 5 & 1058.8 & 141.8 & 896.2 & 1211.8 & \\
\hline \multirow{4}{*}{ CA125 } & Serous cystadenocarcinoma & 17 & 727.0 & 883.8 & 24.1 & 2640.0 & \multirow{4}{*}{$0.027^{*}$} \\
\hline & $\begin{array}{l}\text { Mucinous } \\
\text { cystadenocarcinoma }\end{array}$ & 14 & 553.0 & 446.3 & 27.9 & 1200.0 & \\
\hline & $\begin{array}{l}\text { Endometroid } \\
\text { adenocarcinoma }\end{array}$ & 4 & 100.4 & 93.7 & 33.1 & 237.0 & \\
\hline & Border line tumor & 5 & 280.8 & 175.3 & 72.1 & 527.0 & \\
\hline \multirow{4}{*}{ CEA } & Serous cystadenocarcinoma & 17 & 7.5 & 14.1 & 0.8 & 60.0 & \multirow{4}{*}{0.531} \\
\hline & $\begin{array}{l}\text { Mucinous } \\
\text { cystadenocarcinoma }\end{array}$ & 14 & 14.6 & 30.3 & 0.0 & 103.0 & \\
\hline & $\begin{array}{l}\text { Endometroid } \\
\text { adenocarcinoma }\end{array}$ & 4 & 1.4 & 1.0 & 0.4 & 2.5 & \\
\hline & Border line & 5 & 2.2 & 1.4 & 0.8 & 4.1 & \\
\hline
\end{tabular}




\section{Serum analysis}

We found that the hepatocyte growth factor level in control group ranged from 571.29-1917.1 $\mathrm{pg} / \mathrm{ml}$ with a mean value of $1367.1 \pm 369.7$, while in cases ranged from 896.22-6246.6 pg/ml with a mean value of $1864.42 \pm 1042.1$ implying a significant increase in HGF level in cases than control $(\mathrm{p}<0.001)$.

It was found that the level of HGF was significantly lower in border line cases with a mean value of $1058.8 \pm 141.8 \mathrm{pg} / \mathrm{ml}$ while the level of the marker was at its highest point in serous tumor with a mean value of $2467.7 \pm 1368.1 \mathrm{pg} / \mathrm{ml}$ followed by mucinous tumor in which HGF reached the mean value of $1559.6 \pm 210.0$ $\mathrm{pg} / \mathrm{ml}$ and in the endometroid tumor the level of HGF had a mean value of $1374.4 \pm 136.6 \mathrm{pg} / \mathrm{ml}$.

In this study, the CA125 showed a significantly lower value in borderline cases with a mean value of $280.8 \pm 175.3 \mathrm{U} / \mathrm{ml}$ compared to those in serous tumor with a mean value of $727.0 \pm 883.8 \mathrm{U} / \mathrm{ml}$.

\section{DISCUSSION}

In this study, the mean age in cases was $60.5 \pm 12.06$ while in control it was $46.33 \pm 6.94$. There was statistical significance between the studied groups according to age; this means that ovarian malignancy tends to occur in advanced age groups. In agreement with this study, Aune et al. 2011 in his pilot study stated that ovarian malignancy tends to occur in advanced age group with median age of 63.7 in cases group in comparison to 58.9 in control group. ${ }^{21}$

Regarding the menstrual status in this study, about $32.5 \%$ of cases were pre-menopause compared to $95 \%$ in control group. However, $67.5 \%$ of cases were postmenopausal compared to 5\% in control group. There was statistical significance between studied groups according to menopausal status. Despite the fact that Jacob et al reported $41 \%$ prevalence in postmenopausal women, Szatkowski et al found in contrast to our study that $42.4 \%$ of ovarian cancer patients are in a postmenopausal status while $57.6 \%$ are still menstruating raising the fact that it's important to screen for malignant adnexal masses even in premenopausal women. ${ }^{22,23}$

Joung et al stated in his study that the bioavailable ovarian steroid hormone that occurs in diabetes mellitus are also considered potentially carcinogenic conditions for breast, endometrium, and ovaries in women. ${ }^{24}$ This is in agreement with our study in which Diabetes Mellitus is found in 32.5\% of cases when compared to only $12.5 \%$ in control group.

In the present study, $35(87.5 \%)$ cases were malignant, and $5(12.5 \%)$ cases were borderline. As regard histopathological finding, the most frequent was serous (42.5\%) and mucinous (35\%) followed by endometrioid (10\%). Aune et al reported $48.3 \%$ for serous tumors, $24.6 \%$ for endometrioid type, $11.6 \%$ for clear cell patients, $10 \%$ for Mixed tumor and only $5 \%$ for the mucinous type. ${ }^{21}$

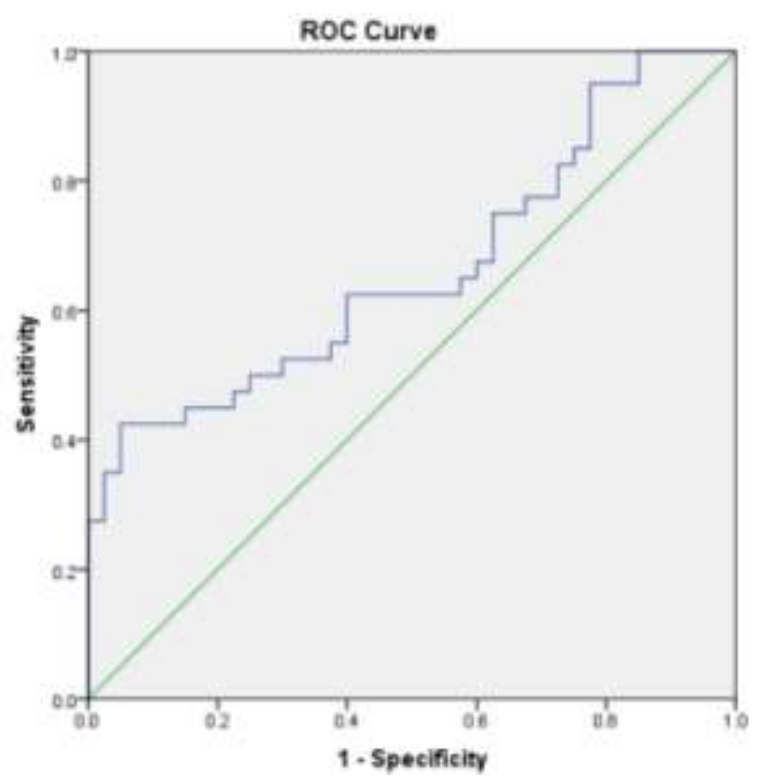

Figure 5: ROC curve for HGF to diagnose cases.

Regards the staging of the malignant cases in the present study, $5(14.3 \%$ ) cases were stage I (Ia, Ib, Ic were $2.9 \%$, $2.9 \%$ and $8.6 \%$ respectively), $5(14.3 \%)$ cases were Stage II, $25(71.6 \%)$ cases were Stage III (IIIa and IIIb were $25.7 \%$ and $45.7 \%$ respectively). Aune et al in his study reported $21(35 \%)$ cases stage I, $3(5 \%)$ cases were Stage II, $30(50 \%)$ cases were Stage III and $6(10 \%)$ cases were Stage IV. ${ }^{21}$

Regarding imaging modalities used in this study, we found that there was a significant increase in detection of ascitis in patients using CT scan (55\%) compared to U/S (32\%).This shows that CT is superior to ultrasonography in detecting ascitis and metastatic deposits. However, there was no statistical difference between the two modalities in detecting bilaterality, loculi and solid component in tumors of the studied cases.

In the present study, the mean CA125 level in the 40 suspected ovarian cancer patients was $547.66 \pm 659.06$ $\mathrm{U} / \mathrm{ml}$ which is lower than levels reported by Aune et al, who reported that median level of CA125 was $625 \mathrm{U} / \mathrm{ml}$. In this study, the CA125 showed a significantly lower value in borderline cases with a mean value of $280.8 \pm 175.3 \mathrm{U} / \mathrm{ml}$ compared to those in serous tumor with a mean value of $727.0 \pm 883.8 \mathrm{U} / \mathrm{ml}^{21}$

Regarding the tumor marker in this study, we found that the hepatocyte growth factor level in control group ranged from $571.29-1917.1 \mathrm{pg} / \mathrm{ml}$ with a mean value of 1367.1 \pm 369.7 , while in cases ranged from 896.22-6246.6 $\mathrm{pg} / \mathrm{ml}$ with a mean value of $1864.42 \pm 1042.1$ implying a significant increase in HGF level in cases than control $(\mathrm{p}<0.001)$.This is in accordance to Aune et al. ${ }^{21}$ 
This study also illustrated the relation between the level of hepatocyte growth factor in serum and various histopathological findings. It was found that the level of HGF was significantly lower in border line cases with a mean value of $1058.8 \pm 141.8 \mathrm{pg} / \mathrm{ml}$ while the level of the marker was at its highest point in serous tumor with a mean value of $2467.7 \pm 1368.1 \mathrm{pg} / \mathrm{ml}$.

From the Receiver Operating Characteristic (ROC) Curve Analysis, its obvious that a hepatocyte growth factor is an important tool for screening and diagnosis of adnexal masses suspicious for ovarian malignancy. The area under the curve (AUC) was 0.71 which is statistically significant. The best cut-off point that maximizes the diagnosis is $844 \mathrm{pg} / \mathrm{ml}$. At this level, the sensitivity is 97.5, and the specificity is 42.0 .The positive predictive value is 83.1 , and negative predictive value is 57.1 .

\section{CONCLUSION}

Our study showed that serum hepatocyte growth factor level was elevated in $71 \%$ of patients with ovarian cancer by histopathology using a quantitative ELISA. Serum HGF level can be used to differentiate between benign gynaecological pathologies, borderline ovarian tumor as well as malignant ovarian tumors.

\section{ACKNOWLEDGEMENTS}

I would like to pay special thankfulness, warmth and appreciation to all the faculty, residents and staff members of the Obstetrics and Gynecology Department at the University of Alexandria, Egypt, whose services turned my research a success.

\section{Funding: No funding sources} Conflict of interest: None declared

Ethical approval: The study was approved by the Institutional Ethics Committee

\section{REFERENCES}

1. Ferlay J, Soerjomataram I, Dikshit R, Eser S, Mathers C, Rebelo M, et al. Cancer incidence and mortality worldwide: sources, methods and major patterns in Globocan 2012. Int J Cancer. 2015;136(5):E359-86.

2. Rossing MA, Wicklund KG, Cushing-Haugen KL, Weiss NS. Predictive value of symptoms for early detection of ovarian cancer. J Natl Cancer Inst. 2010;102(4):222-9.

3. Buys SS, Partridge E, Greene MH, Prorok PC, Reding D, Riley TL, et al. Ovarian cancer screening in the Prostate, Lung, Colorectal and Ovarian (PLCO) cancer screening trial: findings from the initial screen of a randomized trial. Am J Obstet Gynecol. 2005;193(5):1630-9.

4. Visintin I, Feng Z, Longton G, Ward DC, Alvero $\mathrm{AB}$, Lai $\mathrm{Y}$, et al. Diagnostic markers for early detection of ovarian cancer. Clin Cancer Res. 2008;14(4):1065-72.

5. Mor G, Visintin I, Lai Y, Zhao H, Schwartz P, Rutherford T, et al. Serum protein markers for early detection of ovarian cancer. Proc Natl Acad Sci U S A. 2005;102(21):7677-82.

6. Li AJ. New biomarkers for ovarian cancer: OVA1 and ROMA in diagnosis selective use of these new tests may lead to better outcomes for women with adnexal masses or epithelial ovarian cancer. Contemporary OB/Gyn. 2012;57(4):1-7.

7. Kawaguchi M, Kataoka H. Mechanisms of Hepatocyte Growth Factor Activation in Cancer Tissues. Cancers. 2014;6(4):1890-904.

8. Rosen DG, Wang L, Atkinson JN, Yu Y, Lu KH, Diamandis EP, et al. Potential markers that complement expression of CA125 in epithelial ovarian cancer. Gynecol Oncol. 2005;99(2):267-77.

9. American College of Obstetricians and Gynecologists. Practice Bulletin no. 83: Management of Adnexal Masses. Washington, DC: American College of Obstetricians and Gynecologists; 2007.

10. Zhang H, Kong B, Qu X, Jia L, Deng B, Yang Q. Biomarker discovery for ovarian cancer using SELDI-TOF-MS. Gynecol Oncol. 2006;102(1):61-6.

11. Nagakawa O, Yamagishi T, Fujiuchi Y, Junicho A, Akashi T, Nagaike, et al. Serum hepatocyte growth factor activator (HGFA) in benign prostatic hyperplasia and prostate cancer. Eur Urol. 2005;48(4):686-90.

12. Tanaka K, Miki C, Wakuda R, Kobayashi M, Tonouchi H, Kusunoki M. Circulating level of hepatocyte growth factor as a useful tumor marker in patients with early-stage gastric carcinoma. Scand J Gastroenterol. 2004;39(8):754-60.

13. Maulik G, Shrikhande A, Kijima T, Ma PC, Morrison PT, Salgia R. Role of the hepatocyte growth factor receptor, c-Met, in oncogenesis and potential for therapeutic inhibition. Cytokine Growth Factor Rev. 2002;13(1):41-59.

14. Tanimoto S, Fukumori T, El-Moula G, Shiirevnyamba A, Kinouchi S, Koizumi T, et al. Prognostic significance of serum hepatocyte growth factor in clear cell renal cell carcinoma: comparison with serum vascular endothelial growth factor. J Med Investig. 2008;55(1-2):106-11.

15. Stack MS, Fishman DA. Ovarian Cancer. New York: Springer; 2013.

16. Baykal C, Ayhan A, Al A, Yüce K, Ayhan A. Overexpression of the c-Met/HGF receptor and its prognostic significance in uterine cervix carcinomas. Gynecol Oncol. 2003;88(2):123-9.

17. Seidel C, Børset M, Turesson I, Abildgaard N, Sundan A, Waage A. Elevated serum concentrations of hepatocyte growth factor in patients with multiple myeloma. The Nordic Myeloma Study Group. Blood. 1998;91(3):806-12.

18. Corps AN, Sowter HM, Smith SK. Hepatocyte growth factor stimulates motility, chemotaxis and 
mitogenesis in ovarian carcinoma cells expressing high levels of c-me. Int J Cancer. 1997;73(1):151-5.

19. Sawada K, Radjabi AR, Shinomiya N, Kistner E, Kenny H, Becker AR, et al. c-Met overexpression is a prognostic factor in ovarian cancer and an effective target for inhibition of peritoneal dissemination and invasion. Cancer Res. 2007;67(4):1670-9.

20. Bu R, Uddin S, Bavi P, Hussain AR, Al-Dayel F, Ghourab S, et al. HGF/c-Met pathway has a prominent role in mediating antiapoptotic signals through AKT in epithelial ovarian carcinoma. Lab Invest. 2011;91(1):124-37.

21. Aune G, Lian AM, Tingulstad S, Torp SH, Forsmo $\mathrm{S}$, Reseland JE, et al. Increased circulating hepatocyte growth factor (HGF): a marker of epithelial ovarian cancer and an indicator of poor prognosis. Gynecol Oncol. 2011;121(2):402-6.
22. Jacobs IJ, Menon U, Ryan A, Gentry-Maharaj A, Burnell M, Kalsi JK. Ovarian cancer screening and mortality in the UK Collaborative Trial of Ovarian Cancer Screening (UKCTOCS): a randomized controlled trial. Lancet. 2015;387:945-56.

23. Szatkowski W, Blecharz P, Mitus JW, Jasiowka M, Luczynska E, Jakubowicz J. Prognostic factors in Polish patients with BRCA1-dependent ovarian cancer. Hered Cancer Clin Pract. 2016;14:4.

24. Joung $\mathrm{KH}$, Jeong JW, $\mathrm{Ku} \mathrm{BJ}$. The association between type 2 diabetes mellitus and women cancer: the epidemiological evidences and putative mechanisms. Biomed Res Int. 2015:920618.

Cite this article as: Ahmed ZM, Abdel Satar H, Zaki MA, Hassan HM. Comparative study between serum level of hepatocyte growth factor and CA-125 in patients with suspicious malignant adnexal masses. Int J Reprod Contracept Obstet Gynecol 2017;6:38-43. 